Research Article

\title{
Blood Pressure Control and Associations with Social Support among Hypertensive Outpatients in a Developing Country
}

\author{
Luu Quang Thuy, ${ }^{1}$ Nguyen Hoang Thanh $\mathbb{D}^{2},{ }^{2}$ Le Hong Trung, ${ }^{3}$ Pham Huy Tan, ${ }^{4}$ \\ Hoang Thi Phuong Nam, ${ }^{5}$ Pham Thi Diep, ${ }^{6}$ Tran Thi Ha An, ${ }^{7}$ Bui Van San, \\ Tran Nguyen Ngoc, ${ }^{2}$ and Ngo Van Toan ${ }^{2}$ \\ ${ }^{1}$ Vietnam Viet-Duc Hospital, Hanoi 100000, Vietnam \\ ${ }^{2}$ Hanoi Medical University, Hanoi 100000, Vietnam \\ ${ }^{3}$ Vinh Phuc General Hospital, Vinh Phuc 100000, Vietnam \\ ${ }^{4}$ Hanoi Medical University Hospital, Hanoi 100000, Vietnam \\ ${ }^{5}$ National Geriatric Hospital, Hanoi 100000, Vietnam \\ ${ }^{6}$ Faculty of Health Sciences, Thang Long University, Hanoi 100000, Vietnam \\ ${ }^{7}$ National Institute of Mental Health, Bach Mai Hospital, Hanoi 100000, Vietnam
}

Correspondence should be addressed to Nguyen Hoang Thanh; nguyenht.hmu@gmail.com

Received 8 August 2020; Revised 30 January 2021; Accepted 20 March 2021; Published 5 April 2021

Academic Editor: Bishwajit Ghose

Copyright (C) 2021 Luu Quang Thuy et al. This is an open access article distributed under the Creative Commons Attribution License, which permits unrestricted use, distribution, and reproduction in any medium, provided the original work is properly cited.

\begin{abstract}
Relationships between social support characteristics with blood pressure control and recommended behaviors in Vietnamese hypertensive patients have not been investigated. This study is aimed at examining the role of social support characteristics in hypertension control and behaviors. Patients with hypertension $(n=220)$ in Hanoi, Vietnam, were recruited into a crosssectional study. Both functional and structural characteristics of social support and network were examined. Results showed that increasing total network size was related to $52 \%$ higher odds of uncontrolled hypertension (adjusted OR $=1.52,95 \% \mathrm{CI}=$ $1.22-1.89$ ). Higher network sizes on the provision of information support related to advice, emotional support related to decisions, and practical support related to sickness were associated with lower odds of uncontrolled hypertension. Every additional $1 \%$ of the percentage of network members having hypertension decreased $2 \%$ the odds of uncontrolled hypertension (adjusted $\mathrm{OR}=0.98,95 \% \mathrm{CI}=0.96-1.00$ ). A $1 \%$ additional network members who were living in the same household was associated with a decrease of 0.08 point of behavioral adherence score (coef. $=-0.08 ; 95 \% \mathrm{CI}=-0.12-0.03$ ). Meanwhile, a $1 \%$ increase of network members who were friends on the provision of practical support related to sickness and jobs was related to an increase of 0.10 point and 0.19 point of behavioral adherence score (coef. $=0.10 ; 95 \% \mathrm{CI}=0.04-$ 0.17 and coef. $=0.19 ; 95 \% \mathrm{CI}=0.06-0.32$, respectively). The current study suggested that further interventions to improve hypertension management should address the potential effects of social network characteristics.
\end{abstract}

\section{Introduction}

People are now living longer but more vulnerable to noncommunicable diseases (NCDs) [1]. Hypertension is one of the most common NCDs, with more than one billion people experiencing this disease worldwide $[2,3]$. Timely diagnosis and appropriate treatment are essential to control hyperten- sion as well as prevent its severe complications such as cardiovascular diseases, stroke, or kidney failure [4]. However, it is estimated that more than half of patients cannot control their blood pressure, even in hospitals where hypertensive medications and follow-up care are provided freely [5-7]. Nonmedication adherence and unhealthy lifestyles are major reasons of uncontrolled hypertension [8], suggesting the 
matter of the fact that healthcare providers have a limited role in managing this disease [9].

Changing healthy behaviors seems not to be easy because it requires enormous efforts and motivations from each individual [10]. Motivations can be improved when patients receive support and encouragement from their community or family $[11,12]$. In other words, patients' social context is critically important for their health enhancement. The social network, or social relationships, is defined as "a social structure made of individuals (or organizations) that represents "nodes", and they are associated with one or more types of interdependency, such as friendship, common interests, work, knowledge, prestige, and many other interests [13]. Network members of one individual can be anyone who has interaction with this individual (partner, siblings, parents, friends, etc.). Previous literature underlined the association between social support/network and reduced risk of physical and mental health problems as well as mortality [14-17]. People with well-social connectedness were more likely to have healthy behaviors and better life satisfaction $[18,19]$. These relationships have been observed in many patients groups with different health conditions such as overweight/obesity, substance use, depression, and cancer screening [20-24]. Owning a larger and more diverse social network is found to improve self-esteem, which can alleviate the physiological reactivity, improve immune system, and buffer psychological distress [25-27]. In low- and middleincome countries, prior studies suggested the critical role of social support as safety nets, particularly for middle-age and older adults $[28,29]$.

In the hypertensive community, several studies indicated the positive influence of both functional (e.g., social, emotional, or practical support) and structural (e.g., network size or type of relationship) social support and network characteristics of patients on the prevalence of hypertension, blood pressure control, or hypertensive complications. For example, a study in Korean older adults revealed that people with a larger social network size were less likely to suffer from hypertension [30], while another study in Nigeria showed that a high degree of family support was associated with better hypertension control [31]. Moreover, social interventions have been proposed to be more useful to prevent hypertension than interventions that only concentrated on individual factors [32]. Therefore, exploring the functional and structural characteristics of social support in patients with high blood pressure is vital for appropriate hypertension management.

In this study, we aimed to examine the role of social support and network characteristics in hypertension control and adherence of recommended behaviors among hypertensive patients managed at an urban hospital in Hanoi, Vietnam.

\section{Materials and Methods}

2.1. Study Settings, Participants, and Sampling Procedure. Data of this analysis were from a cross-sectional study implemented at an urban hospital in Hanoi, Vietnam, from August to October 2019. There were approximately two thousand outpatients with hypertension who registered for hyperten- sion management in this hospital. The protocol of this study was approved by the institutional review board of the hospital. We recruited outpatients aged 18 years or above who were confirmedly diagnosed with high blood pressure based on the guideline of the Vietnam Ministry of Health (persistently systolic blood pressure level of $\geq 140 \mathrm{mmHg}$ and/or persistently diastolic blood pressure level $\geq 90 \mathrm{mmHg}$ ) [33]. Other eligible criteria included (1) visiting outpatient clinics of the hospital during the study period, (2) accepting to be participants of this study and giving their written informed consent. Patients were excluded if they were inpatients or had disabilities and other cognitive impairments which affected their ability to answer the face-to-face interview.

To calculate the sample size, we employed the formula to estimate a proportion with specified relative precision with confidencelevel $=95 \%$ and expected proportion of uncontrolled hypertension among treated hypertensive patients = $64.0 \%$ (according to a previous study in Central Vietnam [34]). The total sample size was 217 patients. In practice, we recruited 225 patients to prevent those who did not complete the interview. Data of 220 people were included in the data analysis (completion rate $=97.8 \%$ ).

A convenient sampling procedure was performed to recruit patients. First, patients who visited outpatient clinics during the study period for regular hypertension examination and treatment were screened the eligible criteria (such as physical and mental health) by the physicians at the clinics. Then, when they completed all examination procedures (including blood pressure measures), patients were invited to become study participants by the research team and go to a private counseling room for protecting their confidentiality. They were provided a short description of the study and their rights as participants. A face-to-face interview was performed afterward, following by weight and height measures.

2.2. Data Collection and Measurement. The data collection team included undergraduate medical students from the Hanoi Medical University. Before collecting the data, they participated in intensive training sessions about interview skills with patients having high blood pressure, as well as the data collection procedure to ensure their consistency in data collection. They also participated in the pilot study with five patients to assure that they followed correctly the data collection guideline. A structured questionnaire was developed and piloted in these five patients to check the validity and reliability of the questionnaire. During the data collection, one student was in charge of the interview, and another student measured the weight and height of patients. Following variables were collected:

2.2.1. Uncontrolled Hypertension. When patients had regular medical examinations, their office blood pressure was measured by the hospital's physicians using the Japanese Alpk2 sphygmomanometer. After completing the interview, our data collector extracted this information from the patient's medical record. Patients having a systolic blood pressure level of $\geq 140 \mathrm{mmHg}$ and/or diastolic blood pressure level $\geq 90$ 
mmHg were classified into the "uncontrolled" group; otherwise, they were categorized into the "controlled" group [33].

2.2.2. Behavioral Adherence. Eight items from the Conditionspecific Recommendations and Adherence scale were used to assess the adherence of patients with different recommended behaviors for patients with hypertension [35]. These behaviors consisted of (1) take prescribed medication daily, (2) follow a low-salt diet, (3) follow a low-fat diet, (4) exercise regularly, (5) stop/cut down on smoking, (6) cut down on alcohol, (7) cut down on stress, and (8) carry supplies needed for self-care. There were six response options for each behavior: $0=$ none of the time, $1=$ a little of the time, $2=$ some of the time, 3 = a good bit of the time, $4=$ most of the time, and $5=$ all of the time. The total score was $0-40$, and patients with $32 / 40$ points were categorized as "overall health behavior adherence"; otherwise, they were categorized into the "overall non-adherence" group [35].

2.2.3. Social Support and Network Characteristics. In this study, we examined both functional and structural network characteristics of hypertensive patients by using a name generator method, which is one of the most common approaches to explore the individual's egocentric network [36, 37]. An egocentric network is a network that considers each patient (i.e., "ego") a center of the network. A person having relationships with the ego was recorded as a network member (i.e., alter) $[36,37]$. This method helps to figure out the social network of each participant as well as identify the general characteristics of each network member [36, 37]. In this study, we adapted the previous study [38] and used five questions, including

(1) "In the last six months, who was the one that advises you when you had problems?" (informational support related to advice)

(2) "In the last six months, who was the one that could offer their help when you were sick?" (practical support related to sickness)

(3) "In the last six months, who was the one that could offer their emotional support when you were feeling unwell?" (emotional support related to discomfort)

(4) "In the last six months, who was the one that could help you to perform the housework?" (practical support related to jobs)

(5) "In the last six months, who was the one that could discuss important matters with you?" (emotional support related to decisions)

Patients were asked to call as many names as they could remember for each question. The name could be duplicated between questions but could not be duplicated within each question. We then calculate the participants' network size by summing the total number of unique alters in the questionnaire. We also asked patients to report some general characteristics of each network member, including gender, relationship with the participant (e.g., family member, people living in the same household, and friend or others), living place, contact frequency (daily/weekly/monthly/yearly), and whether having hypertension or not. Marital status and whether participating in social activities or not were also examined.

2.2.4. Other Covariates. Other information was collected including age, gender, education, occupation, living area, smoking and alcohol drinking status, comorbidities, weight, height, body mass index, and health-related quality of life. The Short-form 12 version 2 (SF-12v2) instrument investigates HRQoL of hypertensive patients regarding physical component (PCS-12) and mental component (MCS-12) [39, 40].

2.3. Statistical Analysis. We used the Stata software 14.0 for data analysis. Descriptive analyses were conducted to examine the differences in social network characteristics between patients with controlled/uncontrolled hypertension and between patients with behavioral adherence/nonadherence. Chi-squared tests and Mann-Whitney tests were performed as appropriate. Multivariate logistic and tobit regression models were used to explore the association of network variables with uncontrolled hypertension (yes/no) and behavioral adherence score. In this study, we conducted four models for each dependent variable. Model 1 was adjusted for age and sex, while model 2 was adjusted for age, sex, and quality of life (PCS-12 and MCS-12). Model 3 was additionally adjusted for body mass index and number of comorbidities, while model 4 was additionally adjusted for smoking and alcohol use. Multicollinearity was checked by using variance inflation factor (VIF). VIF results showed no multicollinearity among variables. Akaike information criterion (AIC) and Bayesian information criterion (BIC) were then calculated to examine the sensitivity of the models. The level of statistical significance was set at the $5 \%$ level.

\section{Results}

There were 220 hypertensive patients included in the study. The mean age was 64 years (SD 8.9 years). There were $10.9 \%$ of patients having lower secondary education level, $44.5 \%$ being current self-employed, and $40.5 \%$ being retired. Most participants $(81.8 \%)$ were living with their partners and living in urban areas (85.5\%). There were $54.6 \%$ reporting that participated in social activities. The majority of patients did not smoke $(60.9 \%)$. The rate of uncontrolled hypertension was $40.5 \%$, while the rate of adherence with recommended behaviors was $30.4 \%$.

Table 1 shows the social support and network characteristics of hypertensive patients. Patients with uncontrolled hypertension had a significantly higher percentage of network members living in the same households who offered information support $(p<0.05)$ compared to those with controlled hypertension. Meanwhile, participants having adherence with recommended behaviors had a significantly higher percentage of network members who are friends on the provision of practical support-related jobs than that of their nonadherence counterparts $(p<0.05)$. Moreover, in 
TABLE 1: Social support and network characteristics of hypertensive patients according to control of hypertension conditions and behavioral adherence conditions.

\begin{tabular}{|c|c|c|c|c|c|c|}
\hline \multirow[b]{2}{*}{ Characteristics of social network } & \multicolumn{3}{|c|}{ Controlled hypertension $^{\mathrm{a}}$} & \multicolumn{3}{|c|}{ Behavioral adherence $^{\mathrm{a}}$} \\
\hline & $\begin{array}{c}\text { Yes } \\
(n=131)\end{array}$ & $\begin{array}{c}\text { No } \\
(n=89)\end{array}$ & $\begin{array}{c}p \\
\text { value }\end{array}$ & $\begin{array}{c}\text { Yes } \\
(n=66)\end{array}$ & $\begin{array}{c}\text { No } \\
(n=151)\end{array}$ & $\begin{array}{c}p \\
\text { value }\end{array}$ \\
\hline Total network size & $5.3 \pm 6.5$ & $4.8 \pm 7.8$ & 0.92 & $5.8 \pm 7.1$ & $5.5 \pm 6.4$ & 0.70 \\
\hline \multicolumn{7}{|l|}{ Providing informational support related to advice } \\
\hline Network size & $2.1 \pm 2.1$ & $4 \pm 6.5$ & 0.33 & $5.4 \pm 4.6$ & $2.2 \pm 1.9$ & 0.59 \\
\hline Percentage of network members who are daily contact & $21.1 \pm 25.8$ & $39.4 \pm 42.3$ & 0.39 & $42 \pm 36.4$ & $25.2 \pm 17.6$ & 0.23 \\
\hline Percentage of network members who are family members & $17.1 \pm 23.3$ & $34.9 \pm 40$ & 0.25 & $38.5 \pm 34.2$ & $21.3 \pm 15.7$ & 0.34 \\
\hline Percentage of network members who are friends & $13.6 \pm 9.8$ & $32.1 \pm 27.6$ & 0.35 & $31.1 \pm 29.1$ & $12.8 \pm 11$ & 0.65 \\
\hline Percentage of network members who are living in the same household & $6.3 \pm 15.6$ & $21.7 \pm 32.7$ & 0.03 & $30.7 \pm 15.2$ & $12.8 \pm 4.2$ & 0.17 \\
\hline Percentage of network members who are having hypertension & $7.1 \pm 6.1$ & $21 \pm 21.5$ & 0.32 & $22.8 \pm 16$ & $6.8 \pm 5.3$ & 0.82 \\
\hline \multicolumn{7}{|l|}{ Providing emotional support related to discomfort } \\
\hline Network size & $2.9 \pm 3.5$ & $2.8 \pm 4.2$ & 0.31 & $3.3 \pm 5.4$ & $2.6 \pm 2.8$ & 0.60 \\
\hline Percentage of network members who are daily contact & $73.6 \pm 43.7$ & $72 \pm 44.6$ & 0.78 & $73 \pm 44.4$ & $73 \pm 43.9$ & 0.90 \\
\hline Percentage of network members who are family members & $57.9 \pm 47.8$ & $64.5 \pm 47.2$ & 0.32 & $61.3 \pm 47.8$ & $60.2 \pm 47.6$ & 0.88 \\
\hline Percentage of network members who are friends & $18 \pm 36.6$ & $9.9 \pm 28.9$ & 0.07 & $9.9 \pm 27.9$ & $17.1 \pm 36.2$ & 0.18 \\
\hline Percentage of network members who are living in the same household & $43.9 \pm 45.4$ & $52.5 \pm 46.6$ & 0.23 & $45.3 \pm 45$ & $48.6 \pm 46.7$ & 0.74 \\
\hline Percentage of network members who are having hypertension & $14.1 \pm 29.4$ & $12.7 \pm 29$ & 0.50 & $19.8 \pm 35.5$ & $10.8 \pm 25.8$ & 0.08 \\
\hline \multicolumn{7}{|l|}{ Providing emotional support related to decisions } \\
\hline Network size & $2.7 \pm 3.3$ & $2.8 \pm 4.9$ & 0.45 & $3.3 \pm 5.5$ & $2.5 \pm 3.1$ & 0.20 \\
\hline Percentage of network members who are daily contact & $75.4 \pm 41.2$ & $71.2 \pm 43$ & 0.51 & $74.6 \pm 39.8$ & $73.4 \pm 42.8$ & 0.98 \\
\hline Percentage of network members who are family members & $79.8 \pm 40.1$ & $75.3 \pm 43.4$ & 0.45 & $80.3 \pm 40.1$ & $77.2 \pm 41.9$ & 0.59 \\
\hline Percentage of network members who are friends & $2.3 \pm 15$ & $2.1 \pm 13.9$ & 0.97 & $4.3 \pm 20$ & $1.3 \pm 11.5$ & 0.15 \\
\hline Percentage of network members who are living in the same household & $55.7 \pm 44.3$ & $55.8 \pm 44.9$ & 0.92 & $52.4 \pm 42$ & $57.6 \pm 45.7$ & 0.44 \\
\hline Percentage of network members who are having hypertension & $13.2 \pm 28.8$ & $14 \pm 31.2$ & 0.77 & $15.6 \pm 30.1$ & $12.6 \pm 29.8$ & 0.10 \\
\hline \multicolumn{7}{|l|}{ Providing practical support related to sickness } \\
\hline Network size & $3.5 \pm 3.1$ & $3.6 \pm 3.9$ & 0.43 & $3.8 \pm 3$ & $3.4 \pm 3.6$ & 0.10 \\
\hline Percentage of network members who are daily contact & $78.7 \pm 38.1$ & $79.9 \pm 37.3$ & 0.87 & $74.5 \pm 39.7$ & $81.2 \pm 37$ & 0.16 \\
\hline Percentage of network members who are family members & $81.2 \pm 36.6$ & $81.6 \pm 38$ & 0.75 & $80.9 \pm 36$ & $81.2 \pm 38$ & 0.56 \\
\hline Percentage of network members who are friends & $3.6 \pm 15.5$ & $2.4 \pm 13.7$ & 0.37 & $4.3 \pm 14.4$ & $2.7 \pm 15$ & 0.09 \\
\hline Percentage of network members who are living in the same household & $58.1 \pm 41.1$ & $62.8 \pm 40.6$ & 0.42 & $56.5 \pm 38.6$ & $62.2 \pm 41.8$ & 0.31 \\
\hline Percentage of network members who are having hypertension & $10 \pm 21.9$ & $9.1 \pm 23.3$ & 0.29 & $10.6 \pm 21.2$ & $9.2 \pm 23.2$ & 0.14 \\
\hline \multicolumn{7}{|l|}{ Providing practical support related to jobs } \\
\hline Network size & $1.8 \pm 1.8$ & $2.4 \pm 4$ & 0.16 & $2.4 \pm 4.5$ & $1.9 \pm 1.9$ & 0.60 \\
\hline Percentage of network members who are daily contact & $69.3 \pm 45.9$ & $69.6 \pm 45.1$ & 0.93 & $65.9 \pm 46.3$ & $71 \pm 45.1$ & 0.43 \\
\hline Percentage of network members who are family members & $69.6 \pm 45.8$ & $71.2 \pm 45.1$ & 0.85 & $68.9 \pm 46.2$ & $70.9 \pm 45.2$ & 0.82 \\
\hline Percentage of network members who are friends & $0.8 \pm 8.7$ & $1 \pm 9.1$ & 0.79 & $2.8 \pm 16.1$ & $0.0 \pm 0.0$ & 0.03 \\
\hline Percentage of network members who are living in the same household & $62 \pm 47.4$ & $60.5 \pm 46.5$ & 0.70 & $55.7 \pm 47.3$ & $64.2 \pm 46.7$ & 0.21 \\
\hline Percentage of network members who are having hypertension & $14.1 \pm 32.1$ & $8.4 \pm 23.6$ & 0.20 & $10.7 \pm 25.6$ & $11.6 \pm 29.8$ & 0.36 \\
\hline Living with spouse/partners (\%) & 80.9 & 83.2 & 0.67 & 80.3 & 82.8 & 0.66 \\
\hline Participation in social activities (\%) & 56.5 & 51.7 & 0.48 & 66.7 & 50.3 & 0.03 \\
\hline
\end{tabular}

${ }^{\mathrm{a}}$ Expressed as mean $\pm \mathrm{SD}$.

the behavioral adherence group, the percentage of patients participating in the social activities $(66.7 \%)$ was significantly higher than that of the behavioral nonadherence group $(50.3 \%, p<0.05)$.
Table 2 reveals that overall, increasing total network size was related to $52 \%$ higher odds of uncontrolled hypertension (adjusted OR $=1.52,95 \% \mathrm{CI}=1.22-1.89$ ). However, higher network sizes on the provision of information support 
TABLE 2: Relationship between social network characteristics and controlled blood pressure.

\begin{tabular}{|c|c|c|c|c|}
\hline \multirow[b]{2}{*}{ Characteristics of social network } & \multicolumn{4}{|c|}{ Uncontrolled hypertension (yes/no) $^{\mathrm{a}}$} \\
\hline & $\begin{array}{l}\text { OR }(95 \% \text { CI }) \\
\text { Model } 1^{\mathrm{b}}\end{array}$ & $\begin{array}{l}\text { OR }(95 \% \text { CI }) \\
\text { Model } 2^{\mathrm{c}}\end{array}$ & $\begin{array}{l}\text { OR }(95 \% \mathrm{CI}) \\
\text { Model } 3^{\mathrm{d}}\end{array}$ & $\begin{array}{l}\text { OR }(95 \% \mathrm{CI}) \\
\text { Model } 4^{\mathrm{e}}\end{array}$ \\
\hline Total network size & $1.45^{* * *}(1.20-1.77)$ & $1.47^{* * *}(1.21-1.80)$ & $1.47^{* * *}(1.20-1.81)$ & $1.52^{* * *}(1.22-1.89)$ \\
\hline \multicolumn{5}{|l|}{ Providing informational support related to advice } \\
\hline Network size & $0.77^{* * *}(0.65-0.90)$ & $0.76^{* * *}(0.64-0.90)$ & $0.77^{* * *}(0.65-0.91)$ & $0.76^{* * *}(0.64-0.91)$ \\
\hline Percentage of network members who are daily contact & $1.00(0.98-1.02)$ & $1.00(0.98-1.01)$ & $1.00(0.98-1.01)$ & $1.00(0.98-1.01)$ \\
\hline $\begin{array}{l}\text { Percentage of network members who are family } \\
\text { members }\end{array}$ & $1.01(0.99-1.02)$ & $1.00(0.99-1.02)$ & $1.00(0.99-1.02)$ & $1.00(0.99-1.02)$ \\
\hline Percentage of network members who are friends & $1.00(0.99-1.02)$ & $1.00(0.99-1.02)$ & $1.00(0.98-1.02)$ & $1.00(0.98-1.02)$ \\
\hline $\begin{array}{l}\text { Percentage of network members who are living in the } \\
\text { same household }\end{array}$ & $1.02^{*}(1.00-1.04)$ & $1.02(1.00-1.04)$ & $1.02(0.99-1.04)$ & $1.01(0.99-1.04)$ \\
\hline $\begin{array}{l}\text { Percentage of network members who are having } \\
\text { hypertension }\end{array}$ & $1.00(0.98-1.02)$ & $1.00(0.98-1.03)$ & $1.01(0.98-1.03)$ & $1.01(0.99-1.04)$ \\
\hline \multicolumn{5}{|l|}{ Providing emotional support related to discomfort } \\
\hline Network size & $0.92(0.79-1.06)$ & $0.91(0.78-1.06)$ & $0.92(0.78-1.07)$ & $0.89(0.76-1.05)$ \\
\hline Percentage of network members who are daily contact & $0.99^{*}(0.97-1.00)$ & $0.99(0.97-1.01)$ & $0.99(0.97-1.01)$ & $0.99(0.97-1.01)$ \\
\hline $\begin{array}{l}\text { Percentage of network members who are family } \\
\text { members }\end{array}$ & $1.01(0.99-1.03)$ & $1.01(0.99-1.03)$ & $1.00(0.98-1.02)$ & $1.00(0.98-1.02)$ \\
\hline Percentage of network members who are friends & $1.00(0.98-1.01)$ & $0.99(0.98-1.01)$ & $0.99(0.98-1.01)$ & $0.99(0.97-1.01)$ \\
\hline $\begin{array}{l}\text { Percentage of network members who are living in the } \\
\text { same household }\end{array}$ & $1.00(0.99-1.02)$ & $1.01(0.99-1.02)$ & $1.01(0.99-1.02)$ & $1.01(0.99-1.03)$ \\
\hline $\begin{array}{l}\text { Percentage of network members who are having } \\
\text { hypertension }\end{array}$ & $1.00(0.98-1.01)$ & $1.00(0.98-1.01)$ & $0.99(0.98-1.01)$ & $0.99(0.98-1.01)$ \\
\hline \multicolumn{5}{|l|}{ Providing emotional support related to decisions } \\
\hline Network size & $0.86^{* *}(0.74-0.99)$ & $0.84^{* *}(0.73-0.98)$ & $0.85^{* *}(0.73-0.99)$ & $0.86^{* *}(0.74-1.00)$ \\
\hline Percentage of network members who are daily contact & $0.99(0.98-1.01)$ & $0.99(0.97-1.01)$ & $0.99(0.97-1.01)$ & $0.99(0.97-1.01)$ \\
\hline $\begin{array}{l}\text { Percentage of network members who are family } \\
\text { members }\end{array}$ & $1.00(0.99-1.02)$ & $1.00(0.99-1.02)$ & $1.00(0.99-1.02)$ & $1.00(0.99-1.02)$ \\
\hline Percentage of network members who are friends & $0.97(0.93-1.02)$ & $0.98(0.93-1.02)$ & $0.97(0.93-1.02)$ & $0.97(0.93-1.02)$ \\
\hline $\begin{array}{l}\text { Percentage of network members who are living in the } \\
\text { same household }\end{array}$ & $1.00(0.99-1.02)$ & $1.00(0.99-1.02)$ & $1.00(0.99-1.02)$ & $1.00(0.99-1.02)$ \\
\hline $\begin{array}{l}\text { Percentage of network members who are having } \\
\text { hypertension }\end{array}$ & $1.02 *(1.00-1.03)$ & $1.01^{*}(1.00-1.03)$ & $1.02^{*}(1.00-1.03)$ & $1.02^{*}(1.00-1.03)$ \\
\hline \multicolumn{5}{|l|}{ Providing practical support related to sickness } \\
\hline Network size & $0.81^{*}(0.66-1.00)$ & $0.80^{* *}(0.64-1.00)$ & $0.78^{* *}(0.62-0.98)$ & $0.75^{* *}(0.59-0.96)$ \\
\hline Percentage of network members who are daily contact & $1.02 *(1.00-1.04)$ & $1.02^{*}(1.00-1.04)$ & $1.02^{* *}(1.00-1.05)$ & $1.02^{* *}(1.00-1.05)$ \\
\hline $\begin{array}{l}\text { Percentage of network members who are family } \\
\text { members }\end{array}$ & $0.98(0.96-1.00)$ & $0.98(0.96-1.00)$ & $0.98(0.96-1.01)$ & $0.98(0.96-1.01)$ \\
\hline Percentage of network members who are friends & $0.98(0.95-1.02)$ & $0.98(0.95-1.02)$ & $0.98(0.95-1.02)$ & $0.99(0.95-1.03)$ \\
\hline $\begin{array}{l}\text { Percentage of network members who are living in the } \\
\text { same household }\end{array}$ & $1.01(0.99-1.02)$ & $1.01(0.99-1.02)$ & $1.00(0.99-1.02)$ & $1.00(0.98-1.02)$ \\
\hline $\begin{array}{l}\text { Percentage of network members who are having } \\
\text { hypertension }\end{array}$ & $1.00(0.98-1.02)$ & $1.00(0.98-1.02)$ & $1.00(0.98-1.02)$ & $1.00(0.98-1.03)$ \\
\hline \multicolumn{5}{|l|}{ Providing practical support related to jobs } \\
\hline Network size & $0.94(0.74-1.19)$ & $0.95(0.74-1.21)$ & $0.94(0.74-1.20)$ & $0.92(0.71-1.19)$ \\
\hline Percentage of network members who are daily contact & $1.00(0.97-1.03)$ & $1.00(0.97-1.03)$ & $1.00(0.97-1.03)$ & $1.00(0.97-1.03)$ \\
\hline $\begin{array}{l}\text { Percentage of network members who are family } \\
\text { members }\end{array}$ & $1.02(0.99-1.04)$ & $1.01(0.99-1.04)$ & $1.01(0.99-1.04)$ & $1.01(0.99-1.04)$ \\
\hline
\end{tabular}


TABLE 2: Continued.

\begin{tabular}{|c|c|c|c|c|}
\hline \multirow{3}{*}{ Characteristics of social network } & \multicolumn{4}{|c|}{ Uncontrolled hypertension (yes/no) $^{\mathrm{a}}$} \\
\hline & OR $(95 \% \mathrm{CI})$ & OR $(95 \% \mathrm{CI})$ & OR $(95 \% \mathrm{CI})$ & OR $(95 \% \mathrm{CI})$ \\
\hline & Model $1^{\mathrm{b}}$ & Model $2^{\mathrm{c}}$ & Model $3^{\mathrm{d}}$ & Model $4^{\mathrm{e}}$ \\
\hline Percentage of network members who are friends & $1.01(0.93-1.10)$ & $1.01(0.93-1.11)$ & $1.01(0.93-1.10)$ & $1.01(0.92-1.11)$ \\
\hline $\begin{array}{l}\text { Percentage of network members who are living in the } \\
\text { same household }\end{array}$ & $0.99(0.97-1.01)$ & $0.99(0.97-1.01)$ & $1.00(0.98-1.02)$ & $1.00(0.98-1.02)$ \\
\hline $\begin{array}{l}\text { Percentage of network members who are having } \\
\text { hypertension }\end{array}$ & $0.98^{* *}(0.96-1.00)$ & $0.98^{* *}(0.96-1.00)$ & $0.98^{* *}(0.96-1.00)$ & $0.98^{* *}(0.96-1.00)$ \\
\hline Living with spouse/partners (yes vs no) & $1.03(0.41-2.60)$ & $1.03(0.41-2.62)$ & $1.25(0.47-3.32)$ & $1.42(0.52-3.88)$ \\
\hline Participation in social activities (yes vs no) & $0.77(0.38-1.58)$ & $0.79(0.38-1.63)$ & $0.79(0.37-1.68)$ & $0.78(0.35-1.75)$ \\
\hline
\end{tabular}

${ }^{*} p<0.1 ;{ }^{* *} p<0.05 ;{ }^{* * *} p<0.01$; ${ }^{a}$ reference group was controlled hypertension; ${ }^{\mathrm{b}}$ model 1 was adjusted for age and sex; ${ }^{\mathrm{c}}$ model 2 was adjusted for age, sex, and quality of life; ${ }^{\mathrm{d}}$ model 3 was adjusted for age, sex, quality of life, body mass index, and number of comorbidities; ${ }^{\mathrm{e}}$ model 4 was adjusted for age, sex, quality of life, body mass index, number of comorbidities, smoking, and alcohol use.

related to advice, emotional support related to decisions, and practical support related to sickness were associated with lower odds of uncontrolled hypertension. In model 4, every additional $1 \%$ of the percentage of network members who were daily contact on the provision of practical support related to sickness was related to $2 \%$ higher odds of uncontrolled hypertension (adjusted OR $=1.02,95 \% \mathrm{CI}=1.00-$ 1.05 ), while every additional $1 \%$ of the percentage of network member having hypertension decreased $2 \%$ the odds of uncontrolled hypertension (adjusted $\mathrm{OR}=0.98,95 \% \mathrm{CI}=$ $0.96-1.00)$.

Table 3 depicts that regarding networks on informational support related to advise, an additional 1\% in the percentage of network members who were living in the same household was associated with a decrease of 0.08 point of behavioral adherence score (coef. $=-0.08 ; 95 \% \mathrm{CI}=-0.12-0.03)$. Meanwhile, an 1\% increase of network members who were friends on the provision of practical support related to sickness and jobs was related to a 0.10 point and 0.19 point of behavioral adherence score (coef. $=0.10 ; 95 \% \mathrm{CI}=0.04-$ 0.17 and coef. $=0.19 ; 95 \% \mathrm{CI}=0.06-0.32$, respectively). Higher social network sizes on emotional support related to decisions and practical support related to sickness were associated with higher behavioral adherence score, but in model 4 , these associations were not statistically significant $(p>0.05)$. Notably, patients participating in social activities had significantly higher behavioral adherence score compared to those not participating in such activities (coef. $=2.56 ; 95 \% \mathrm{CI}=0.99-4.13)$.

\section{Discussion}

Our study informs an insight into the relationship between functional and structural characteristics of social support and uncontrolled hypertension as well as adherence with recommended behaviors among hypertensive patients in the urban setting of Vietnam. The findings of this study indicated that both functional and structural network characteristics were associated with hypertension control and behavioral adherence. For example, higher network size on the provision of informational support, emotional support related to decisions, and practical support related to sickness was independently associated with a lower like- lihood of uncontrolled hypertension. Moreover, social activity participation appeared to be independently related to a higher behavioral adherence score.

In this study, we have observed that an overall large network size would increase the risk of uncontrolled blood pressure. However, our result differed from a prior study in Korean and American older adults, which showed that hypertensive patients having a large network size would have lower odds of uncontrolled hypertension $[9,30]$. It might justify this difference in sample characteristics and culture. Indeed, $30 \%$ of our patients were still employed ( $<60$ years old), while the patients in other studies were aged 60 years or more. Nonetheless, we found that lower degrees of information support, emotional support, and practical support was considerably related to uncontrolled hypertension, underlining the critical role of different social network aspects in managing hypertension, that echoes previous studies that indicated that insufficient social support was correlated with a higher risk for cardiovascular diseases [38, 41]. Cornwell et al. found that emotional support was associated with a lower risk of uncontrolled hypertension [9]. These authors also revealed that patients who frequently discussed health problems with their network were less likely to have uncontrolled hypertension [9]. However, our study has contradicted this finding since increasing network members who could daily talk about sickness would increase the risk of uncontrolled hypertension. We assumed that regular discussion or communication about health problems might cause the relationships more tense or conflicted, resulting in more stress for patients [42]. On the other hand, patients receiving practical support to their housework/jobs from networks with higher percentages of hypertensive members were less likely to suffer uncontrolled hypertension. This result might emphasize the fact that having peers with hypertension who helped patients in daily activities would be more beneficial to control the disease rather than having a more extensive network size but increasing stress levels in their lives.

Regarding behavioral adherence, we found that patients having more practical support from friends were more likely to adhere to behavioral recommendations. Moreover, higher percentages of network members living in the same household would decrease adherence. In other words, the finding revealed that patients with a centralized network to 
TABLE 3: Relationship between social network characteristics and behavioral adherence.

\begin{tabular}{|c|c|c|c|c|}
\hline \multirow[b]{2}{*}{ Characteristics of social network } & \multicolumn{4}{|c|}{ Behavioral adherence score } \\
\hline & $\begin{array}{l}\text { Coef. }(95 \% \text { CI }) \\
\text { Model } 1^{\text {a }}\end{array}$ & $\begin{array}{l}\text { Coef. }(95 \% \text { CI }) \\
\text { Model } 2^{\text {b }}\end{array}$ & $\begin{array}{l}\text { Coef. }(95 \% \text { CI }) \\
\text { Model } 3^{\mathrm{c}}\end{array}$ & $\begin{array}{l}\text { Coef. }(95 \% \text { CI }) \\
\text { Model } 4^{\mathrm{d}}\end{array}$ \\
\hline Total network size & $0.20(-0.16-0.57)$ & $0.16(-0.21-0.53)$ & $0.15(-0.23-0.52)$ & $0.14(-0.23-0.50)$ \\
\hline \multicolumn{5}{|l|}{$\begin{array}{l}\text { Providing informational support related to } \\
\text { advice }\end{array}$} \\
\hline Network size & $-0.10(-0.41-0.21)$ & $-0.09(-0.40-0.22)$ & $-0.09(-0.40-0.22)$ & $-0.10(-0.40-0.20)$ \\
\hline $\begin{array}{l}\text { Percentage of network members who are daily } \\
\text { contact }\end{array}$ & $-0.01(-0.04-0.03)$ & $-0.00(-0.04-0.03)$ & $0.00(-0.03-0.04)$ & $0.00(-0.03-0.04)$ \\
\hline $\begin{array}{l}\text { Percentage of network members who are } \\
\text { family members }\end{array}$ & $0.03(-0.01-0.06)$ & $0.03^{*}(-0.01-0.07)$ & $0.03(-0.01-0.06)$ & $0.02(-0.01-0.06)$ \\
\hline $\begin{array}{l}\text { Percentage of network members who are } \\
\text { friends }\end{array}$ & $0.01(-0.03-0.04)$ & $0.01(-0.02-0.05)$ & $0.01(-0.03-0.04)$ & $0.01(-0.03-0.04)$ \\
\hline $\begin{array}{l}\text { Percentage of network members who are living } \\
\text { in the same household }\end{array}$ & $-0.06^{* * *}(-0.10-0.02)$ & $-0.07^{* * *}(-0.12-0.03)$ & $-0.07^{* * *}(-0.11-0.03)$ & $-0.08^{* * *}(-0.12-0.03)$ \\
\hline $\begin{array}{l}\text { Percentage of network members who are } \\
\text { having hypertension }\end{array}$ & $0.01(-0.03-0.05)$ & $0.01(-0.04-0.05)$ & $0.01(-0.04-0.05)$ & $0.01(-0.03-0.05)$ \\
\hline \multicolumn{5}{|l|}{$\begin{array}{l}\text { Providing emotional support related to } \\
\text { discomfort }\end{array}$} \\
\hline Network size & $-0.00(-0.31-0.30)$ & $0.00(-0.30-0.31)$ & $0.01(-0.30-0.31)$ & $0.04(-0.26-0.33)$ \\
\hline $\begin{array}{l}\text { Percentage of network members who are daily } \\
\text { contact }\end{array}$ & $-0.01(-0.04-0.03)$ & $0.01(-0.03-0.04)$ & $0.01(-0.03-0.04)$ & $-0.00(-0.04-0.03)$ \\
\hline $\begin{array}{l}\text { Percentage of network members who are } \\
\text { family members }\end{array}$ & $0.02(-0.01-0.06)$ & $0.00(-0.04-0.05)$ & $0.01(-0.04-0.05)$ & $0.01(-0.03-0.05)$ \\
\hline $\begin{array}{l}\text { Percentage of network members who are } \\
\text { friends }\end{array}$ & $-0.01(-0.04-0.02)$ & $-0.02(-0.06-0.01)$ & $-0.02(-0.06-0.01)$ & $-0.02(-0.05-0.01)$ \\
\hline $\begin{array}{l}\text { Percentage of network members who are living } \\
\text { in the same household }\end{array}$ & $-0.01(-0.04-0.02)$ & $-0.01(-0.04-0.02)$ & $-0.01(-0.05-0.02)$ & $-0.01(-0.05-0.02)$ \\
\hline $\begin{array}{l}\text { Percentage of network members who are } \\
\text { having hypertension }\end{array}$ & $0.03 *(-0.00-0.06)$ & $0.03^{*}(-0.00-0.06)$ & $0.03^{*}(-0.00-0.06)$ & $0.03 *(-0.00-0.06)$ \\
\hline \multicolumn{5}{|l|}{ Providing emotional support related to decisions } \\
\hline Network size & $-0.30^{*}(-0.60-0.01)$ & $-0.31^{* *}(-0.62-0.01)$ & $-0.32^{* *}(-0.63-0.01)$ & $-0.26^{*}(-0.56-0.04)$ \\
\hline $\begin{array}{l}\text { Percentage of network members who are daily } \\
\text { contact }\end{array}$ & $0.04^{* *}(0.00-0.08)$ & $0.03(-0.01-0.07)$ & $0.03(-0.01-0.07)$ & $0.03 *(-0.01-0.07)$ \\
\hline $\begin{array}{l}\text { Percentage of network members who are } \\
\text { family members }\end{array}$ & $-0.02(-0.05-0.02)$ & $-0.01(-0.05-0.03)$ & $-0.01(-0.05-0.03)$ & $-0.01(-0.05-0.02)$ \\
\hline $\begin{array}{l}\text { Percentage of network members who are } \\
\text { friends }\end{array}$ & $-0.04(-0.13-0.05)$ & $-0.03(-0.12-0.06)$ & $-0.03(-0.12-0.06)$ & $-0.04(-0.12-0.04)$ \\
\hline $\begin{array}{l}\text { Percentage of network members who are living } \\
\text { in the same household }\end{array}$ & $-0.02(-0.05-0.01)$ & $-0.02(-0.05-0.01)$ & $-0.02(-0.05-0.01)$ & $-0.02(-0.05-0.01)$ \\
\hline $\begin{array}{l}\text { Percentage of network members who are } \\
\text { having hypertension }\end{array}$ & $0.01(-0.03-0.04)$ & $0.01(-0.03-0.04)$ & $0.01(-0.03-0.04)$ & $0.01(-0.03-0.04)$ \\
\hline \multicolumn{5}{|l|}{ Providing practical support related to sickness } \\
\hline Network size & $-0.45 *^{*}(-0.86-0.04)$ & $-0.42^{* *}(-0.83-0.01)$ & $-0.39^{*}(-0.80-0.02)$ & $-0.34^{*}(-0.74-0.06)$ \\
\hline $\begin{array}{l}\text { Percentage of network members who are daily } \\
\text { contact }\end{array}$ & $-0.03(-0.07-0.01)$ & $-0.03(-0.07-0.01)$ & $-0.04^{*}(-0.08-0.01)$ & $-0.03(-0.07-0.01)$ \\
\hline $\begin{array}{l}\text { Percentage of network members who are } \\
\text { family members }\end{array}$ & $0.04(-0.01-0.09)$ & $0.04(-0.01-0.09)$ & $0.04(-0.01-0.09)$ & $0.03(-0.02-0.08)$ \\
\hline $\begin{array}{l}\text { Percentage of network members who are } \\
\text { friends }\end{array}$ & $0.12^{* * *}(0.05-0.19)$ & $0.12^{* * *}(0.05-0.19)$ & $0.12^{* * *}(0.05-0.18)$ & $0.10^{* * *}(0.04-0.17)$ \\
\hline $\begin{array}{l}\text { Percentage of network members who are living } \\
\text { in the same household }\end{array}$ & $0.00(-0.03-0.04)$ & $0.00(-0.03-0.04)$ & $0.01(-0.02-0.04)$ & $0.01(-0.02-0.04)$ \\
\hline $\begin{array}{l}\text { Percentage of network members who are } \\
\text { having hypertension }\end{array}$ & $-0.02(-0.06-0.03)$ & $-0.02(-0.06-0.03)$ & $-0.02(-0.06-0.03)$ & $-0.03(-0.07-0.02)$ \\
\hline
\end{tabular}


TABLE 3: Continued.

\begin{tabular}{|c|c|c|c|c|}
\hline \multirow[b]{2}{*}{ Characteristics of social network } & \multicolumn{4}{|c|}{ Behavioral adherence score } \\
\hline & $\begin{array}{l}\text { Coef. }(95 \% \text { CI }) \\
\text { Model } 1^{\text {a }}\end{array}$ & $\begin{array}{l}\text { Coef. }(95 \% \text { CI }) \\
\text { Model } 2^{\text {b }}\end{array}$ & $\begin{array}{l}\text { Coef. }(95 \% \text { CI }) \\
\text { Model 3c }\end{array}$ & $\begin{array}{l}\text { Coef. }(95 \% \text { CI }) \\
\quad \text { Model } 4^{\mathrm{d}}\end{array}$ \\
\hline \multicolumn{5}{|l|}{ Providing practical support related to jobs } \\
\hline Network size & $0.05(-0.40-0.50)$ & $0.05(-0.41-0.50)$ & $0.04(-0.42-0.49)$ & $0.03(-0.41-0.46)$ \\
\hline $\begin{array}{l}\text { Percentage of network members who are daily } \\
\text { contact }\end{array}$ & $-0.01(-0.07-0.05)$ & $-0.01(-0.07-0.06)$ & $-0.01(-0.07-0.05)$ & $-0.01(-0.07-0.05)$ \\
\hline $\begin{array}{l}\text { Percentage of network members who are } \\
\text { family members }\end{array}$ & $0.02(-0.03-0.07)$ & $0.03(-0.02-0.08)$ & $0.03(-0.02-0.08)$ & $0.03(-0.02-0.08)$ \\
\hline $\begin{array}{l}\text { Percentage of network members who are } \\
\text { friends }\end{array}$ & $0.18^{* * *}(0.04-0.31)$ & $0.18^{* * *}(0.05-0.32)$ & $0.19^{* * *}(0.06-0.32)$ & $0.19^{* * *}(0.06-0.32)$ \\
\hline $\begin{array}{l}\text { Percentage of network members who are living } \\
\text { in the same household }\end{array}$ & $-0.01(-0.05-0.03)$ & $-0.02(-0.06-0.03)$ & $-0.02(-0.06-0.03)$ & $-0.02(-0.06-0.02)$ \\
\hline $\begin{array}{l}\text { Percentage of network members who are } \\
\text { having hypertension }\end{array}$ & $-0.02(-0.05-0.02)$ & $-0.02(-0.05-0.02)$ & $-0.02(-0.05-0.02)$ & $-0.01(-0.05-0.02)$ \\
\hline Living with spouse/partners (yes vs no) & $1.20(-0.87-3.26)$ & $1.30(-0.76-3.36)$ & $1.18(-0.90-3.25)$ & $0.77(-1.23-2.78)$ \\
\hline Participation in social activities (yes vs no) & $2.54^{* * *}(0.96-4.11)$ & $2.22^{* * *}(0.63-3.81)$ & $2.29^{* * *}(0.70-3.89)$ & $2.56^{* * *}(0.99-4.13)$ \\
\hline
\end{tabular}

household members were at higher risk of nonadherence. Another notable finding is that participating in social activities would increase the level of behavioral adherence. It should be noted that two-thirds of our samples were 60 years old or more. Previous literature suggested that older people should be encouraged to have an extensive social network and participate in social activities to promote their autonomy and social roles, which could increase their physical and mental health [43-45]. These findings suggest the critical social network-based preventive strategies to encourage behavioral adherence among hypertensive patients. More studies should be elucidated to clarify these relationships.

The findings of this study pose several implications for public health and clinical practitioners. First, physicians should pay attention to the social relationships of hypertensive patients and the influences of these relationships with hypertensive treatment and behaviors. Awareness of patients' social support and social network can help to develop effective and tailored interventions based on the network characteristics for improving treatment outcomes and lifestyle behaviors. Second, our results support the development of tailored social network-based interventions to prevent uncontrolled blood pressure among hypertensive patients. Second, further studies should be warranted to examine the role of different network characteristics in the treatment progress and the development of hypertensive complications. Third, we believed that social support and network characteristics also had an important role in the onset of hypertension $[9,46]$, which should be resolved in future interventions to prevent hypertension in the community. Moreover, further behavioral change interventions should take into account the social network, which has been shown in the previous literature that can help to improve the adoption of public health interventions [47].

This study has strengths, including the use of several validated instruments such as SF-12v2 and Condition-specific
Recommendations and Adherence scale, which allowed study findings to be comparable to previous research in the world. Moreover, we employed a name generator, which is among the most common method to explore the egocentric network of each person [36, 37]. The associations between social network variables and our outcomes of interests were also adjusted for well-known potential confounders. However, several methodological limitations should be acknowledged. First, the nature of the cross-sectional design in this study did not allow us to have a causal conclusion regarding the associations. Second, patients should recall the names in their social network, which might lead to recall bias. Third, we performed this study in only one hospital, which might decrease our ability to generalize the finding to the general hypertensive population in Vietnam.

\section{Conclusions}

The current study showed that higher network sizes on the provision of informational support, emotional support related to decisions, and practical support related to sickness were associated with a lower likelihood of uncontrolled hypertension. Findings also revealed that social support and network characteristics were related to hypertension control and adherence with recommended behaviors. Further interventions to improve hypertension management should address the potential effects of social network characteristics.

\section{Data Availability}

A data availability statement is compulsory for research articles and clinical trials. Here, requests for access to individual subject data may be made to Nguyen Hoang Thanh: please send an email to nguyenht.hmu@gmail.com| nguyenhoangthanh@hmu.edu.vn. 


\section{Conflicts of Interest}

The authors declare that they have no conflicts of interest.

\section{Authors' Contributions}

Luu Quang Thuy and Nguyen Hoang Thanh equally contributed to this work and are co-first authors.

\section{References}

[1] K.-H. Wagner and H. Brath, "A global view on the development of non communicable diseases," Preventive Medicine, vol. 54, pp. S38-S41, 2012.

[2] P. M. Kearney, M. Whelton, K. Reynolds, P. Muntner, P. K. Whelton, and J. He, "Global burden of hypertension: analysis of worldwide data," The Lancet, vol. 365, no. 9455, pp. 217223, 2005.

[3] K. T. Mills, J. D. Bundy, T. N. Kelly et al., "Global disparities of hypertension prevalence and control: a systematic analysis of population-based studies From 90 countries," Circulation, vol. 134, no. 6, pp. 441-450, 2016.

[4] B. Sakboonyarat, R. Rangsin, A. Kantiwong, and M. Mungthin, "Prevalence and associated factors of uncontrolled hypertension among hypertensive patients: a nation-wide survey in Thailand," BMC Research Notes, vol. 12, no. 1, p. 380, 2019.

[5] M. R. Akpa, D. I. Agomuoh, and O. J. Odia, "Drug compliance among hypertensive patients in Port Harcourt, Nigeria," Nigerian journal of medicine, vol. 14, no. 1, pp. 55-57, 2006.

[6] Y. Ostchega, C. F. Dillon, J. P. Hughes, M. Carroll, and S. Yoon, "Trends in hypertension prevalence, awareness, treatment, and control in older U.S. adults: data from the National Health and nutrition examination survey 1988 to 2004," Journal of the American Geriatrics Society, vol. 55, no. 7, pp. 10561065, 2007.

[7] D. J. Hyman and V. N. Pavlik, "Characteristics of patients with uncontrolled hypertension in the United States," The New England journal of medicine, vol. 345, no. 7, pp. 479-486, 2001.

[8] B. L. Salako, F. A. Ajose, and E. Lawani, "Blood pressure control in a population where antihypertensives are given free," East African medical journal, vol. 80, no. 10, pp. 529-531, 2004.

[9] E. Y. Cornwell and L. J. Waite, "Social network resources and management of hypertension," Journal of health and social behavior, vol. 53, no. 2, pp. 215-231, 2012.

[10] N. Heijmans, J. van Lieshout, and M. Wensing, "Social network composition of vascular patients and its associations with health behavior and clinical risk factors," PLoS One, vol. 12, no. 9, article e0185341, 2017.

[11] A. V. Chobanian, G. L. Bakris, H. R. Black et al., "The seventh report of the joint national committee on prevention, detection, evaluation, and treatment of high blood pressure: the JNC 7 report," Journal of the American Medical Association, vol. 289, no. 19, pp. 2560-2572, 2003.

[12] R. dos Santos Costa and L. T. Nogueira, "Family support in the control of hypertension," Revista latino-americana de enfermagem, vol. 16, no. 5, pp. 871-876, 2008.

[13] I. Masic, S. Sivic, S. Toromanovic, T. Borojevic, and H. Pandza, "Social networks in improvement of health care," Materia Socio Medica, vol. 24, no. 1, pp. 48-53, 2012.
[14] F. Mookadam and H. M. Arthur, "Social support and its relationship to morbidity and mortality after acute myocardial infarction: systematic overview," Archives of internal medicine, vol. 164, no. 14, pp. 1514-1518, 2004.

[15] B. Nausheen, Y. Gidron, R. Peveler, and R. Moss-Morris, "Social support and cancer progression: a systematic review," Journal of Psychosomatic Research, vol. 67, no. 5, pp. 403415, 2009.

[16] L. F. Berkman, T. Glass, I. Brissette, and T. E. Seeman, "From social integration to health: Durkheim in the new millennium ${ }^{\text {it }}$, Social science \& medicine, vol. 51, no. 6, pp. 843857, 2000, Epub 2000/09/06.

[17] D. Umberson and J. K. Montez, "Social relationships and health: a flashpoint for health policy," Journal of health and social behavior, vol. 51, 1_suppl, pp. S54-S66, 2010.

[18] D. Umberson, "Gender, marital status and the social control of health behavior," Social science \& medicine, vol. 34 , no. 8 , pp. 907-917, 1992.

[19] D. Umberson, R. Crosnoe, and C. Reczek, "Social relationships and health behavior across life course," Annual review of sociology, vol. 36, no. 1, pp. 139-157, 2010.

[20] N. A. Christakis and J. H. Fowler, "The collective dynamics of smoking in a large social network," The New England journal of medicine, vol. 358, no. 21, pp. 2249-2258, 2008.

[21] J. N. Rosenquist, J. H. Fowler, and N. A. Christakis, "Social network determinants of depression," Molecular psychiatry, vol. 16, no. 3, pp. 273-281, 2011.

[22] J. N. Rosenquist, J. Murabito, J. H. Fowler, and N. A. Christakis, "The spread of alcohol consumption behavior in a large social network," Annals of internal medicine, vol. 152, no. 7, pp. 426-33, W141, 2010.

[23] K. W. Strully, J. H. Fowler, J. M. Murabito, E. J. Benjamin, D. Levy, and N. A. Christakis, "Aspirin use and cardiovascular events in social networks," Social science \& medicine, vol. 74, no. 7, pp. 1125-1129, 2012.

[24] N. L. Keating, A. J. O'Malley, J. M. Murabito, K. P. Smith, and N. A. Christakis, "Minimal social network effects evident in cancer screening behavior," Cancer, vol. 117, no. 13, pp. 3045-3052, 2011.

[25] A. Steptoe, N. Owen, S. R. Kunz-Ebrecht, and L. Brydon, "Loneliness and neuroendocrine, cardiovascular, and inflammatory stress responses in middle-aged men and women," Psychoneuroendocrinology, vol. 29, no. 5, pp. 593-611, 2004.

[26] L. C. Hawkley and J. T. Cacioppo, "Loneliness matters: a theoretical and empirical review of consequences and mechanisms," Annals of behavioral medicine, vol. 40, no. 2, pp. 218-227, 2010.

[27] P. A. Thoits, "Mechanisms linking social ties and support to physical and mental health," Journal of health and social behavior, vol. 52, no. 2, pp. 145-161, 2011.

[28] R. M. Gyasi, D. R. Phillips, and K. Abass, "Social support networks and psychological wellbeing in community-dwelling older Ghanaian cohorts," International psychogeriatrics, vol. 31, no. 7, pp. 1047-1057, 2019.

[29] J. van Willigen and N. K. Chadha, "Social networks of old people in India: research and policy," Journal of aging \& social policy, vol. 15, no. 2-3, pp. 109-124, 2003.

[30] J. Baek, N. W. Hur, H. C. Kim, and Y. Youm, "Sex-specific effects of social networks on the prevalence, awareness, and control of hypertension among older Korean adults," Journal of geriatric cardiology, vol. 13, no. 7, pp. 580-586, 2016. 
[31] O. S. Ojo, S. O. Malomo, and P. T. Sogunle, "Blood pressure (BP) control and perceived family support in patients with essential hypertension seen at a primary care clinic in Western Nigeria," Journal of family medicine and primary care, vol. 5, no. 3, pp. 569-575, 2016.

[32] C. F. Mendes de Leon, T. A. Glass, and L. F. Berkman, "Social engagement and disability in a community population of older adults: the New Haven EPESE," American journal of epidemiology, vol. 157, no. 7, pp. 633-642, 2003, Epub 2003/04/04.

[33] Health Mo, Decision 3192 / QD-BYT in 2010 issuing guidance on measuring and treatment hypertension, Ministry of Health, Hanoi, 2010.

[34] H. A. Hien, N. M. Tam, V. Tam, A. Derese, and D. Devroey, "Prevalence, awareness, treatment, and control of hypertension and its risk factors in (Central) Vietnam," International journal of hypertension, vol. 2018, Article ID 6326984, 12 pages, 2018.

[35] R. L. Kravitz, R. D. Hays, C. D. Sherbourne et al., "Recall of recommendations and adherence to advice among patients with chronic medical conditions," Archives of internal medicine, vol. 153, no. 16, pp. 1869-1878, 1993.

[36] P. V. Marsden, "Network data and measurement," Annual review of sociology, vol. 16, no. 1, pp. 435-463, 1990.

[37] L. McCallister and C. S. Fischer, "A procedure for surveying personal networks," Sociological Methods \& Research, vol. 7, no. 2, pp. 131-148, 2016.

[38] S. Brinkhues, N. H. T. M. Dukers-Muijrers, C. J. P. A. Hoebe et al., "Social network characteristics are associated with type 2 diabetes complications: The Maastricht Study," Diabetes Care, vol. 41, no. 8, pp. 1654-1662, 2018.

[39] D. Turner-Bowker and S. J. Hogue, "Short Form 12 Health Survey (SF-12)," in Encyclopedia of Quality of Life and WellBeing Research, A. C. Michalos, Ed., pp. 5954-5957, Springer Netherlands, Dordrecht, 2014.

[40] J. Ware, M. Kosinski, D. Turner-Bowker, and B. Gandek, "How to score SF-12 items," SF-12 v2: How to Score Version 2 of the SF-12 Health Survey, pp. 29-38, Health Institute, New England Medical Center, Boston, Massachusetts, 2002.

[41] K. Orth-Gomér, A. Rosengren, and L. Wilhelmsen, "Lack of social support and incidence of coronary heart disease in middle-aged Swedish men," Psychosomatic Medicine, vol. 55, no. 1, pp. 37-43, 1993.

[42] T. Seeman and X. Chen, "Risk and protective factors for physical functioning in older adults with and without chronic conditions: MacArthur studies of successful aging," The journals of gerontology Series B, Psychological sciences and social sciences, vol. 57, no. 3, pp. S135-S144, 2002, Epub 2002/05/02.

[43] A. Bowling, "Quality of life in older age: what older people say," in Social Indicators Research Series, pp. 15-30, Springer, 2007.

[44] N. T. Huong, L. T. H. Ha, and T. Q. Tien, "Determinants of health-related quality of life among elderly: evidence from chi Linh town, Vietnam," Asia Pacific Journal of Public Health, vol. 29, 5, Supplement, pp. 84S-93S, 2017.

[45] T. Van Nguyen, H. Van Nguyen, T. Duc Nguyen, T. Van Nguyen, and N. T. The, "Difference in quality of life and associated factors among the elderly in rural Vietnam," Journal of Preventive Medicine and Hygiene, vol. 58, no. 1, pp. E63-E71, 2017.
[46] F. T. Shaya, V. V. Chirikov, C. D. Mullins et al., "Social networks help control hypertension," Journal of clinical hypertension, vol. 15, no. 1, pp. 34-40, 2013.

[47] D. A. Kim, A. R. Hwong, D. Stafford et al., "Social network targeting to maximise population behaviour change: a cluster randomised controlled trial," The Lancet, vol. 386, no. 9989, pp. 145-153, 2015. 